\title{
Business Network Simulation: Combining Research Cases and Agent-Based Models in a Robust Methodology
}

\author{
Frans Prenkert \\ BI Norwegian Business School, Center for Cooperative Studies \\ Department of Innovation and Economic Organisation, NO-0442 Oslo, Norway \\ Tel: 47-46-410-559Ｅ-mail: frans.prenkert@bi.no
}

Received: October 5, 2012

Accepted: November 1, 2012

Online Published: November 9, 2012

doi:10.5430/ijba.v3n6p82

URL: http://dx.doi.org/10.5430/ijba.v3n6p82

\begin{abstract}
This paper describes the use of an agent-based model (ABM) with the purpose of simulating interaction processes in business networks. Such an ABM must be able to capture time and process in networks while retaining a level of comprehension and overview. The ABM rests on the assumption that business networks can be viewed as complex adaptive systems (CAS) and draws on the opportunities to build and use ABMs to simulate processes in such systems. This paper outlines the conceptual foundations and the methodological challenges and opportunities associated with such an endeavor with special reference to issues concerning the modeling of the complexities of business networks. Specifically it discusses the use of $\mathrm{ABM}$ and research case in combination in an effort to produce a robust methodology. It contributes with suggestions on how one concretely can handle these issues and challenges when using ABMs to model non-linear dynamic interaction processes in networks.
\end{abstract}

Keywords: Social simulation, Agent-based models, Multi-agent simulation, Business networks, Interaction, Complexity, Process

\section{Introduction}

How entities such as business relationships and networks develop over time is an area that is generally under-researched. Despite being a recurring theme in the field of industrial marketing (Holmen, Pedersen, \& Torvatn, 1999; Håkansson \& Snehota, 1995; Medlin, 2004; Aastrup, 2000), there is still a gap in our understanding of how business networks develop and evolve over time and the roles managers and governments and other actors play in these processes (Wilkinson, 2008). One reason for the relatively little research on time and process in business networks can be due to the inherent challenges associated with both the associated conceptualizations and methodologies (Halinen, Medlin \& Törnroos , 2012; Halinen \& Törnroos, 2005; Medlin, 2004).

In this circumstance, the argument in this paper is that there may be a remedy to this methodological challenge. I argue that we can model time and process in business networks in a fruitful way by considering these networks to be complex adaptive systems (CASs) and that we can investigate them by the use of agent-based simulation models (ABMs) run on ordinary desktop computers. This gives us the opportunity to view time and process through the lens of complexity science-a view that I argue to be very helpful when it comes to dealing with both the conceptualization problem and the methodological challenges associated with time and process in business networks, indeed with the complexities of management and organizational research in general as suggested by Harrison, Lin, Carroll, \& Carley (2007). In relation to business networks, this is recognized by Ian Wilkinson:

"A major gap in understanding business relations and networks is the way they develop and evolve over time [...] this gap exists because most research and theory to date is dominated by comparative-static, variance-based, survey-type approaches to describing and explaining relationship and network behavior and performance, which ignore temporal processes including development and evolution, interaction and order effects, and feedback effects. The overall aim must be, therefore, to build agent-based models (ABMs) of such business relationship and network development and evolution as complex adaptive systems." (Wilkinson, 2008: 265)

Wilkinson develops his line of argument as follows:

"The traditional focus of research on static, variance-based models of business markets, tested often with one-shot cross-sectional surveys, has reached the limits of its usefulness. The models developed and tested typically assume 
one-way causal processes among variables ripped from their contexts and the ongoing behavioural processes of which they are a part. While these methods have proved valuable in forcing us to spell out the logic of our models and to take care in the way we measure relevant variables, they cannot tell us much about the causal mechanisms at work and are a far cry from the ongoing actions, reactions and events characterizing real markets, transactions, relations and networks." (Wilkinson, 2008: 264)

I draw on, and supplement this argument in this paper suggesting a way to conceptualize and investigate time and process in business networks that is not hampered by the assumption of static, variance-based models. Time and process must be accounted for. As is expressed by Brian Arthur, time and process are essential parts of CASs:

"Time enters naturally here via adjustment and change: as the elements react, the aggregate changes, as the aggregate changes, elements react anew. Barring some asymptotic state or equilibrium reached, complex systems are systems in process, systems that constantly evolve and unfold over time." (Arthur, 1999: 107)

The challenge with this is that recognizing the inherently dynamic and processual character of business networks as CASs, we quickly reaches a level of complexity that is considerable. This means that we need to develop approaches and tools which we can use in our investigations of such phenomena. Arthur (1999: 107) recognizes this:

“...economic 'elements' - human agents - react with strategy and foresight by considering outcomes that might result as a consequence of behavior they might undertake. This adds a layer of complication to economics not experienced in the natural sciences."

Viewing business networks as CASs implies an interest in the study of the formation of patterns in these networks. Or differently expressed-how we can explain and model how the decentralized local interactions among heterogeneous autonomous agents in business networks generate some observed regularities in terms of macro-level patterns. The central issue thus becomes how we can arrive at generative explanations of business networks. Joshua Epstein, in suggesting a generative approach to social science acknowledges this and indicates the need for a new scientific instrument to investigate questions of this kind - the generativist's questions: "How could the decentralized local interactions of heterogeneous autonomous agents generate the given regularity?" (Epstein, 2006: 5).

In order to investigate this kind of questions based on a conceptualization of business networks as CASs, we need to develop methods and models, because complexity economics "...is not an adjunct to standard economic theory, but a theory at a more general, out-of-equilibrium level" (Arthur, 1999: 7). By incorporating complexity economics into business network analysis and using ABMs to model networks some of the issues can be handled. Most concretely, what can be handled using ABM is the problem with complexity that immediately arises from these points of departures. CASs are characterized by the fact that the elements interact in such a way so as to generate non-linear patterns, involving positive feedback loops and emergence.

The review of the literature shows a lack in prior research to produce research tools and methodologies to handle sand-pile pink-noise out-of-equilibrium dynamics which is so ubiquitous outside standard economic models. This point to the overall problem that this paper deals with: How can we develop research tools that enable us to handle issues such as non-linearity, positive feedback, causal loops and emergence in a concrete way without loosing overview and comprehension to complexity? The purpose is to present a research tool which helps enhancing our investigations of interactions in business networks when seen as CASs, thus not making the mainstream standard equilibrium assumption. The overall aim is to contribute to and further our understanding of time and processes in out-of-equilibrium systems such as business networks.

\section{Towards a Research Tool: Case-Based Agent-Based Modeling}

This is not the place to go into the technical details concerning multi-agent systems modeling as it is well covered elsewhere (see for example Railsback \& Grimm [2012] and Epstein \& Axtell [1996]), The type of ABM used here displays the characteristics described by Axelrod \& Cohen (1999), Dooley \& Van de Ven (1999), Epstein (2006), Epstein \& Axtell (1996), and Simon $(1955,1976)$. The argument is that ABMs provide a tool to model local interactions in multi-agent systems based on some micro-specifications that are sufficient to generate interesting macro-structures (Epstein, 2006). Talking about business networks populated by social beings, these models must be able to model all the main psychological, social, managerial and economic mechanisms operating in such networks (Wilkinson, 2008). Obviously ABMs are capable of this type of modeling of very complex dynamic phenomena. However, I posit here that such models can be strengthened to create relevant analyses. To that end, we can combine these tools with another well-known, but sometimes misused tool; the research case. 


\subsection{The Research Case}

ABMs need to be complemented with empirical data in order to provide practice relevant explanations and understanding. This means that multi-agent systems modelers must test the agreement between the real-world and the macro structures that has been generated (Epstein, 2006). This is usually referred to as the validation of a model and will be discussed later. Such validations of the fit between simulated macro structures and actual real-world behavior and structures can be done with the help of a range of tools ranging from statistical analysis to case-based validation (Balchi, 1994; Epstein, 2006). I suggest the use of a research case to validate the model because the multi-agent system produce macro-level outputs based on micro-level interactions yielding 'sand-pile' dynamics (Dooley \& Van de Ven, 1999), also known as pink noise dynamics in time series analysis. In these systems small changes in micro-level structures can (but must not) produce large ripple effects at the macro-level. These patterns are produced because of the basic causal mechanisms being based on multiple interdependent causes and/or because the aggregated behavior depends on simultaneous responses to parallel relaxation processes (Bak, Tang, \& Wiesenfeld, 1988). This is a system that Dooley \& Van de Ven (1999) characterize as high dimensional with non-linear interactions - in our terminology; a CAS. Such systems are inherently difficult to verify using traditional statistical tools (Midgley, Marks, \& Kunchamwar, 2007; Wilensky \& Rand, 2007; Louie \& Carley, 2008; Robinson, 2005).

The research case is the target macro structure-the explanandum (Epstein, 2006). The empirical issue is whether a hypothesized specification of micro-level rules and interactions produces (or generates, or 'grows') the observed macro-level phenomenon. The guiding beacon for generative simulation is that if you did not grow it, you did not explain its emergence (Epstein, 2006). A micro specification may, or may not generate an observed macro phenomenon, and this empirical fallibility qualifies the ABM as a scientific research tool. The research case thus has a crucial role in the approach suggested here as it constitutes the empirical target explanandum.

\subsection{Introducing a Target Explanandum: The North Atlantic Herring Network}

I will use a specific illustrative ABM to exemplify the arguments set forth here (Note 1). The details and specifics of the construction of the ABM as a research tool will be discussed in detail below; however, the specifics of the empirical content will not be included as it has been described in detail elsewhere (see, Følgesvold \& Prenkert, 2009). So I will only make a few necessary notes here.

The target explanandum that is targeted in the ABM used as an example here has been called the North Atlantic Herring Network (Følgesvold \& Prenkert, 2009). This network displays a high level of complexity and adaptation, and it comprises the activities, resources and actors associated with the catching, processing and distribution of herring from the North Atlantic Sea to customers around the world. The network achieving this consists of actors from mainly two nation states; Norway and Iceland. What is interesting with this target case is that these two national sub-networks are very different in some important characteristics.

The main difference between the Norwegian and Icelandic sub-networks lies in the organization between the catch actors, primary processing actors and exporters: In Norway there is a forced market while in Iceland it is not. In contrast to the auction market organization found in Norway, the interaction between fleet and industry in the Icelandic sub-network is characterized by a high degree of vertical integration, in which $70-90 \%$ of all vessels are physically integrated into the greater industry, meaning that primary processing takes place on-board the ship at sea. In terms of ownership and control, this integration also incorporates the export function, which means that the Icelandic suppliers act as completely integrated companies in relationship to their customers abroad.

This distinction is one of the features of the explanandum that the ABM must be able to replicate if it is going to be useful as a representation of the real world network and as a platform for experimentation. But at a more fundamental level, the ABM must be able to handle the issues of time and process in the network. This is the challenge that we shall discuss in this paper.

\section{Time and Process in Agent-Based Models}

One assumption of agent-based modeling is that the micro behavior of agents is logically sufficient to explain macroscopic patterns emerging from these local interactions (Epstein, 2006). The term 'emergence' is opaque in many writings. For an overview of its history in the philosophy of science and its relation to complexity science in general and agent-based modeling in particular, see Epstein, (2006: 31-38). Emergence is defined here as the generation of stable macro-level patterns from the local interactions of agents (Epstein \& Axtell, 1996). The ABM targeting the North Atlantic herring network consists of the following main components: Agents; schemata; tags; connections; environment; fit; boundary; and existence assumptions. These components are not unique to this particular ABM but generic to all ABMs based on complexity science models of CAS (e.g., Gilbert, 2008; Dooley, 
2004).

In the following sections, we shall discuss how aspects of time and process have been implemented in the specifications of such an ABM. The detail of its components; theoretical as well as empirical are not discussed here. For the purposes of this paper, we shall concentrate only on the issues of time and process and how they directly concern the constitutive components of the ABM.

\subsection{Modeling Time: Dynamics in Agent-Based Models}

Modeling time is important because it is over time that local micro-interactions generate emergent macroscopic patterns globally (Guastello, 2002). The ABM focuses on local interactions in terms of the buying/selling interaction (Håkansson \& Prenkert, 2004; Håkansson \& Waluszewski, 2002) among actors in the network(s). Such interaction is high-dimensional (Dooley, 2004) as it is driven by a large number of inter-dependent agents which generates complex pink noise dynamics on the aggregate global level. Pink noise is different from white noise-which is entirely random - in as much as it exhibits dynamics patterns generated from a large number of agents, but which are not independent (as are the interactions that generate white noise). Rather they are semi-autonomous and inter-dependent, which accounts for their apparent constrained randomness which can cause ripple effects. This is due to the nonlinear character of interactions comprising local feedback loops (Dooley, 2004; Schroeder, 1991).

High-dimensional causal systems that exhibit pink noise dynamics are common in society. An economy provides an often-referred-to example (Dooley, 2004). The generative mechanism producing pink noise patterns, or attractors as they are called in dynamic systems (Guastello, 1995), stems from a high-dimensional, multivariable causal system, the components of which interacts extensively. In this ABM, these attractors arise because of the interactions over time among agents acting as buyers and sellers in an international business network setting.

\subsection{Modeling Process: Sequencing of Agent-Based Models}

While time is in principal essential in CAS and in multi-agent systems, a main issue remains to be discussed: How is time translated to an ABM? An ABM rests on the idea that it can be used to simulate processes over time. As the simulation runs, it has a pace defined as periods for which all the algorithms are performed and all variables calculated to produce outputs. For each step, these calculations are reiterated. In the ABM used here to exemplify the suggested approach, the modelers implemented these time periods in such a way as to enable the agents to interact and exchange resources.

A crucial issue concerning the time aspect in agent-based models pertains to the order according to which agents are invoked (Epstein, 2006: 86-87). Simulations proceed as beats of a clock, time being modeled as discrete steps. At each beat, iteration, or period of the simulation, all agents are given a turn to act. The question is in which order the agents should be invoked (Huberman \& Glance, 1993). This is especially important in high-dimensionality dynamic systems such as the one modeled here, because it can affect the way messages and information transmits among agents. In the exemplary ABM the modelers used a random asynchronous execution procedure (Gilbert, 2008: 29) to specify the order of agent invocation meaning that each agent is invoked in a different random order for each iteration or period of the simulation.

One period represents one month of time in the targeted North Atlantic Herring Network and twelve periods in the $\mathrm{ABM}$ thus constitutes a year, and is set to reflect actual, real-world events and fluctuations. The ABM can be set to run any number of steps. Sometimes one may want them to be divisible by twelve during a simulation, because a full year must have passed in order to produce all the output variables that are needed.

Cyclical and natural fluctuations in the multi-agent system were implemented with the help from the research case analysis. This turned out to be of crucial empirical importance when determining the capacity of the primary processors and the volumes of raw material inputted into the two sub-networks of the system, because they differ in relation to network form and are both cyclical as well as linear over time (Følgesvold \& Prenkert, 2009). The target research case informed the modelers that primary processors' capacity is relative to the supply on a period of twelve periods (i.e., on an annual basis). The implication for the ABM is that the capacity is therefore calculated at the beginning of each run, based on initially stated inputs and are thereafter recalculated every twelve periods to reflect the average monthly supply for the coming twelve periods (months).

Again, based on the target research case, the Norwegian primary processors were set to have a maximum capacity based on the capacity of the total Norwegian supply fleet calculated thus:

- $\quad$ Primary-capacity $=\left(\sum\right.$ capacity-Norwegian-suppliers/number-of-Norwegian-primaries $)+$ over-capacity

Icelandic primary processors were set to have a maximum capacity based on the supply fleet that each individual 
processor owns:

- $\quad$ Primary-capacity = Ecapacity-owned-suppliers + over-capacity

This difference in capacities stems from the empirical difference in the network form of the two sub-networks in the targeted research case. Thus such a seemingly straightforward procedure as calculating the primary processors' capacity becomes complicated primarily due to the incorporation of many types of change in the model, but also because of the distinction between the two sub-networks in terms of network form.

Another important feature of $\mathrm{ABM}$ in relation to its sequencing is the implementation of agent-relationship-agent interaction. In situations where agents interact via a relationship, exchange can occur only once each period. At the end of the period, agent schemata are updated to determine effects on both the actor agents and the relationship agents which entail the strengthening or weakening of relationships.

\section{The Generative Process Logic of Agent-Based Models}

So far we have discussed the basic micro specifications of the ABM and the implementation of time. Now we turn to the issue of process. CAS-based ABMs are inherently deductive and mathematical in nature (Epstein, 2006). Is this not counter-intuitive to what have been discussed above? As is the case with all generative models, the ABM used here requires an a priori specified causal model of the relationship among the variables that are of interest (Dooley, 2004). This fundamental model then serves as the generative process logic of the ABM. Here, two important issues deserve elaboration. First, what is the character of causation? And secondly, how is the direction of causation specified?

\subsection{The Character of Causation: Nomogenetic Complexity}

Admittedly, the model depicted in Fig. 1 is deterministic and causal, but emphatically not in the mundane customary sense. In this work and all others including ABMs, as well as in complexity science-indeed in science at large as we shall see - this means that it is based on the principle of determinacy stating that "If similar causes happen under similar conditions, then similar effects are produced by them in most cases." (Bunge, 1979: 51). As specified in general determinism, or neo-determinism (Bunge, 1979), causation is only one among a number of inter-related categories of determination. To use the words of Mario Bunge, the causality exhibited in Fig. 1 is "...no more and no less than a first-order approximation.” (Bunge, 1979: 29). The other categories of determination present in our study are those of structural holistic determination; teleological determination; dialectical determination; and interaction (Bunge, 1979).

As it is used in the ABM, this causal model produces a logic or law in terms of the "forms of patterns of determination" (Bunge, 1979: 18-19), which constrain the dynamical system in question (otherwise it would only produce white noise - pure randomness). Such lawful production (or nomogenesis) based on multiple categories of determination is characteristic of CAS and is the basis for determination in cybernetics and in social science in a broader sense (von Wright, 1971). Thus, the ABM generates complex patterns of determination as its first-order approximation of the relations among variables and is combined with other categories of determination to produce an amalgamated lawfulness. This nomogenetic complexity is the hallmark of CAS and ABMs and stems from the incorporation of many categories of determination at different levels (Bunge, 1979), but it does not make it causal in the traditional (or perhaps mundane) use of the word, since such a label denotes a system void of any nomogenetic complexity. Whenever we use the word causal in this work, it is in the formal sense, denoting a process of nomogenesis that incorporates many levels of categories of determination and exhibiting nomogenetic complexity.

\subsection{The Direction of Causation: Causal Cycles}

One of the most important mechanisms in an ABM is that of positive feedback. Such mechanisms produce non-linear emergent patterns and they comprise causal cycles as opposed to causal series or chains (Rosenblueth, Wiener, \& Bigelow, 1943; Bunge, 1979). Inputs (causes) and outputs (effects) are connected through reciprocal causation, not unidirectional. This complexity has been recognized in relation to business network analysis (Ryan, Tahtinen, Vanharanta \& Mainela, 2012). In the exemplary Herring ABM, the causal model (Fig.1) only specifies the first-order initial approximation of the relationship between network form (NF) and relationship strength (RS), which is the first layer of a set of hierarchically ordered categories of determination (Bunge, 1979). The next level of determination in our causal model is interaction, in which feedback based on causal cycles constitutes the very mechanism of emergence.

The third layer is that of structural determination, which means that the parts are determined by the whole structure. In this ABM, this specifies the initial direction of the causal link in the causal model. This initial direction is also 
theoretically underscored in works on social theory asserting that complex human social systems are morphogenetic in character (Buckley, 1967), based on a stratified reality (both social and natural) (Bhaskar, 1975, 1998), characterized by emergence, and that structure genetically pre-exists agency (Archer, 1995, 1996). Concretely, this means in this ABM that, at the beginning of the morphogenetic cycle, the network form (NF) impacts the strength of the relationships (RS) of the agents, as modeled in Fig. 1, not the other way around.

The fourth layer consists of teleological determination and it is built into the ABM via the agents. These agents are semi-autonomous, acting based on goals specified as heuristics in their schemata (Newell \& Simon, 1972). This type of determination is core to the field of distributed artificial intelligence and originates from cybernetics (von Wright, 1971).

Finally, dialectical determination is likewise a mechanism built into the ABM in terms of the contrasting interests of buyers and sellers in relation to the focal resource (herring). Completed exchange entails agents adapting and adjusting through negotiations to achieve a synthesized solution which impacts the structure of the agents. This modeling of the multi-agent system aim to reflect the very fabric of complex social morphogenetic systems in which the concept of time becomes emphasized (Archer, 1995). For every iteration of the ABM, this dialectic exerts its influence.

All together this produces a causal system of complex lawfulness — or sand pile dynamics—or pink noise dynamics. What this causal system does is to specify the conditions necessary at a microscopic level to produce complex non-linear systems at a macroscopic level. Interaction, teleological and dialectic determination enters the ABM as the core mechanisms controlling agent behavior, whereas causal and structural determination enters the ABM via the causal model. The combined effect yields a CAS characterized by emergence and complexity.

$<$ Insert Figure 1 Here $>$

\section{Specifying and Calibrating an Agent-Based Model}

Empirical data from the research case in this section comes from Følgesvold \& Prenkert (2009). Based on the target research case, the modelers identified a causal link between network form (denoted 'NF') and the strength of the relationships between primary processors/exporters of herring and their buyers (denoted 'RS'). However, this relationship ('1' in Fig. 1.) was not entirely a direct relationship, but one moderated by the variation in the quality of the herring that is the focal resource (denoted 'Input Quality Variation, IQV' in Fig. 1.), and the heterogeneity of the demand residing in the output market (denoted 'Demand Heterogeneity, DH' in Fig. 1.), denoted '2' and ' 3 ' in Fig. 1. According to the modelers, these are variables and relations inferred by the research case. In addition, the case showed that there was also an interaction effect between the 2 and 3 labeled ' 4 ' in Fig. 1. This means that the variables IQV and DH interact to create periodic pink noise dynamics. The research case, finally, inform the modelers that this interaction effect is, in turn, moderated by the level of adaptation to quality demands that sellers make when offering herring to buyers (denoted 'Quality Adaptation, QA' in Fig. 1.). This is also derived from the mechanism of value creation used in the ABM resting on the conceptualization of value as the services a resource can render and actors' adaptation to each other. This generative mechanism adds to the pink noise dynamics as it links to the very local exchange behavior of the agents in the multi-agent system. Turn to Luft \& Shields (2003) for an instructive discussion of variations of causal-model forms.

The dependent variable serves as the variable against which one can plot macro-level patterning of the multi-agent system. It is against this variable that one can read out any results from simulated experiments using the ABM.

\subsection{Testing and Calibrating the Agent-Based Model}

Once the ABM is working and simulations can be run, it needs to be calibrated and tested in order to make sure it is actually doing what it is supposed to do (Balchi, 1994). This is especially important if one is to use the model to perform experiments (Gilbert, 2008; Gilbert \& Troitzsch, 2008). Quality assurance of agent based models, that is the verification of the software coding and the validation of the model specifications, can prove to be problematic. While quite different in nature, the processes of verification and validation both suffer from a lack of consensus on generally accepted methods and procedures (Gilbert, 2008; Midgley, et al., 2007; Troitzsch, 1994; Epstein, 2006). Verification applies to whether or not the actual code is doing what the researcher wants and expects it to, whereas validation applies to whether or not the simulation is a good model of the target it is supposed to represent (Gilbert, 2008). Verification is usually a matter of quality assurance and not a matter of degrees - either an ABM is OK, or it is not. Validation, on the other hand, can be a matter of discretion and degrees of fit between a simulated macrostructure and the empirical target. Indeed, there can be (although it is unusual) multiple alternative micro specifications (i.e., ABMs) that generate the target explanandum, and then one has to decide on the best explanation 
of the observed macro phenomenon (Epstein, 2006).

Essentially, verification involves getting rid of the bugs in the programming code. It may sound easier than it actually is, because most ABMs comprise stochastic elements making comparisons between runs problematic, as each run produces different outputs. Whether a difference in output is to be referred to as a natural stochastic variation of the simulation or whether it derives from a programming error can be difficult to discern.

In the verification of the ABM used as an example here, the modelers tested the coding by the use of some parameter values for case events of which they had a good understanding of likely outputs, and then compared them to runs of the model (Gilbert, 2008). Another way of minimizing the risk of programming errors is to code elegantly, and to use many comments in order to always be able to discern what part of the code does what in the simulation. These hallmarks of coding were adopted. In addition, output diagnostics were also included enabling the control and careful monitoring of intermediary values of variables during the simulation, even as they changed step-by-step as suggested by, among others, Balchi (1994), Gilbert (2008), and Gilbert \& Troitzsch (2008).

Validation procedures are more difficult to carry out and a number of potential error sources exist (Gilbert \& Troitzsch, 2008). Not least of all, it is problematic to gather sufficient quantities of social science data to enable comprehensive systematic validation (Troitzsch, 1994). With this in mind, the modelers proceeded with validation procedures including base-line scenarios and sensitivity testing that included corner testing (Gilbert, 2008) and tests of extreme-bounds to determine the robustness of the ABM (Midgley, et al., 2007; Miller, 1998).

The ABM was then validated through the use of qualitative data from the research case (Midgley, et al., 2007). Qualitative data is necessary for validation because the ABM produce macro-level outputs based on micro-level interactions that yield pink noise dynamics. Such patterns are almost impossible to verify using traditional statistical tools (Midgley, et al., 2007; Wilensky \& Rand, 2007; Louie \& Carley, 2008; Robinson, 2005). Thus, qualitative validation judgments were used at the macro-level (Moss \& Edmonds, 2005). An alternative approach had been to use replication in terms of using two (or more) different types of simulation models and compare the outcomes of these (see e.g., Axtell, Axelrod, Epstein, \& Cohen [1996], Wilensky \& Rand [2007], and Olaru, Denize, \& Purchase [2009]). However, such replication requires the construction of multiple simulation models thus increasing significantly the complexity and the amount of labor involved.

An important next step of the empirical validation of this ABM was to create a baseline scenario. The baseline was constructed in order to create a platform for further experimentation in which the sources of variation would be kept as few as possible in order to reduce as much complexity as possible (Midgley, et al., 2007). This was a way to test the internal model structure and make sure that it worked properly in terms of the mechanisms controlling the dependent variable, and to create a zero-state basis for comparison of subsequent experiments. To ensure that structural differences between the two supply structures, other than the organization between supplier and primary processor, did not have any impact, all other parameters were set equal for the two structures.

\section{Rising to the Challenge: Using Agent-Based Models to Investigate Business Networks}

The construction of the ABM to investigate the North Atlantic herring network draws on two sources of knowledge and understanding of the phenomenon which it is set out to model: First, it uses the theories and conceptualizations of the mechanisms and processes of industrial networks - especially on strength and adaptation in international business relationships, in the ABM used as an example here. Second, it uses empirical qualitative data from the research case of the international North Atlantic Herring Network; the target explanandum.

The benefit of using ABMs to model business networks hinges on how well the generative modeler can get the micro specifications of the ABM to generate the target explanandum. Expressed differently, the challenge is to build an ABM with such specifications of micro-level interactions that it produces the same macro-level patterns as can be observed in empirical accounts of the targeted business network. In the ABM used here it becomes a matter of whether the modelers succeed in modeling the macroscopic patterns of the North Atlantic herring network that is recorded in the research case.

\subsection{Conclusion: Using a Research Case as a Target Explanandum}

The part of the real world on which we focus when attempting to build a representative model is called a "target" in agent-based modeling (Gilbert, 2008; Gilbert \& Troitzsch, 2008). The model is set out to represent the target in some special ways (Scott Poole, 2004; Leik \& Meeker, 1975). The method of using a simulation model in social science comprises a target relating to a model via a process of abstraction; collected data which is gathered on the target; and output of simulations which is aligned to collected data to show some similarity, or analogy in patterns (Gilbert \& Troitzsch, 2008). 
In developing a case study as an interpretation of a target, data and theory usually interact and shape each other in a way typical for both case studies (Dubois \& Gadde, 2002; Ragin, 1992) and simulation as a method (Gilbert \& Troitzsch, 2008). This is helpful when it comes to the interpretation of a usually rather chaotic reality as reflected in empirical data, thus offering a tightening of the study and creating a sense of direction for the enquiry (Ragin, 2000; Miles \& Huberman, 1994).

But why do I suggest a qualitative research case as the target explanandum in this paper? The choice to use a qualitative case study stems from the empirical target: business networks. It entails a high level of complexity - a level of complexity that is inherited to the ABM which thus exhibits a degree of complexity so that we need qualitative data (Miles \& Huberman, 1994; Morgan \& Smircich, 1980) for validation (Moss \& Edmonds, 2005). In addition, I argue that research case studies are particularly suitable for this task as they are good at creating valid accounts of business networks (Dubois \& Gadde, 2002) and for uncovering mechanisms and processes (Pettigrew, 1997), something that is of significance when building an ABM, because it relies on a formalized specification of its mechanisms and processes (Gilbert, 2008). Hence, the choice of a qualitative approach for the validation of ABMs in this context stems from the nature of the phenomena under investigation (Morgan \& Smircich, 1980) - in our case, business networks - and ultimately from the aim of the research: to better our explanations and understandings of complex features of business networks including but not restricted to such things as time and process.

In addition, any ABM must correspond to a target. Performing the act of corresponding the model to the target can never be a completely objective process void of interpretations on the part of the modeler(s) doing it. Data is always interpreted, and in this circumstance details from a scrupulously constructed case is particularly useful in providing a systematic interpretation of the empirical data. The research case can thus be said to constitute a careful conscious systematic interpretation of the target reality - business networks - which is then used to validate the ABM with the ultimate aim to improve our understanding of this target reality by generating explanations from simulations. While this field of research - business network simulation-face great expectations, it also face major challenges, among which the development of common methods for model validation is one that is in need of further scrutiny and refinement.

\section{References}

Aastrup, J. (2000). Change in Networks - A Critical Realist Interpretation. Paper presented at the $16^{\text {th }}$ Industrial Marketing and Purchasing Conference, Bath, United Kingdom, September 7-9.

Archer, M. (1995). Realist Social Theory: The Morphogenetic Approach. Cambridge, UK: Cambridge University Press. http://dx.doi.org/10.1017/CBO9780511557675

Archer, M. (1996). Culture and Agency. The Place of Culture in Social Theory (Revised ed.). Cambridge, UK: Cambridge University Press. http://dx.doi.org/10.1017/CBO9780511557668

Arthur, W. B. (1999). Complexity and the Economy. Science, (284), 107-109. http://dx.doi.org/10.1126/science.284.5411.107

Axelrod, R., \& Cohen, M. D. (1999). Harnessing Complexity: Organizational Implications of a Scientific Frontier. NY: The Free Press.

Axtell, R., Axelrod, R., Epstein, J. M., \& Cohen, M. (1996). Aligning Simulation Models: A Case Study and Results. Computational and Mathematical Organization Theory, 1(2), 123-141. http://dx.doi.org/10.1007/BF01299065

Bak, P., Tang, C., \& Wiesenfeld, K. (1988). Self organized critically. Physical Review A, $38,364$. http://dx.doi.org/10.1103/PhysRevA.38.364

Balchi, O. (1994). Validation, verification, and testing techniques throughout the life cycle of a simulation study. Annals of Operations Research, 53, 121-173. http://dx.doi.org/10.1007/BF02136828

Bhaskar, R. (1975). A Realist Theory of Science. London: Verso.

Bhaskar, R. (1998). Societies. In M. Archer, R. Bhaskar, A. Collier, T. Lawson \& A. Norrie (Eds.), Critical Realism Essential Readings. London: Routledge.

Buckley, W. (1967). Sociology and Modern Systems Theory. Englewood Cliffs, N.J.: Prentice Hall.

Bunge, M. A. (1979). Causality and Modern Science (3rd Revised ed.). New York: Dover Publications.

Dooley, K. J. (2004). Complexity Science Models of Organizational Change and Innovation. In M. Scott Poole \& A. H. Van de Ven (Eds.), Handbook of Organizational Change and Innovation (pp. 354-373). Oxford: Oxford University Press. 
Dooley, K. J., \& Van de Ven, A. H. (1999). Explaining Complex Organizational Dynamics. Organization Science, 10(3), 358-372. http://dx.doi.org/10.1287/orsc.10.3.358

Dubois, A., \& Gadde, L.-E. (2002). Systematic Combining: An Abductive Approach to Case Research. Journal of Business Research, 55(7), 553-560. http://dx.doi.org/10.1016/S0148-2963(00)00195-8

Epstein, J. M. (Ed.). (2006). Generative Social Science: Studies in Agent-Based Computational Modeling. Princeton and Oxford: Princeton University Press.

Epstein, J. M., \& Axtell, R. (1996). Growing artificial societies: Social science from the bottom up. Cambridge, MA.: MIT Press.

Følgesvold, A., \& Prenkert, F. (2009). Magic Pelagic - An agent-based simulation of twenty years of emergent value accumulation in the North Atlantic herring exchange system. Industrial Marketing Management, 38(5), 529-540. http://dx.doi.org/10.1016/j.indmarman.2008.09.004

Gilbert, N. (2008). Agent-Based Models. Thousand Oaks, CA: Sage.

Gilbert, N., \& Troitzsch, K. G. (2008). Simulation for the Social Scientist (2nd ed.). Maidenhead: Open University Press.

Guastello, S. (1995). Chaos, catastrophe, and human affairs. Mahwah, NJ: Erlbaum.

Guastello, S. (2002). Managing emergent phenomena. Mahwah, NJ: Erlbaum.

Halinen, A., Medlin, C. J., \& Törnroos, J.-Å. (2012). Time and process in business network research. Industrial Marketing Management, 41(2), 215-223. http://dx.doi.org/10.1016/j.indmarman.2012.01.006

Halinen, A., \& Törnroos, J.-Å. (2005). Using Case Methods in the Study of Contemporary Business Networks. Journal of Business Research, 58(9), 1285-1297. http://dx.doi.org/10.1016/j.jbusres.2004.02.001

Harrison, J. R., Lin, Z., Carroll, G. R., \& Carley, K. M. (2007). Simulation Modeling in Organizational and Management Research. Academy of Management Review, 32(4), 1229-1245. http://dx.doi.org/10.5465/AMR.2007.26586485

Holmen, E., Pedersen, A.-C., \& Torvatn, T. (1999). Is It Possible to Conceptualise the Interplay Between Structure and Process in the Industrial Network Approach? Paper presented at the 15th Industrial Marketing and Purchasing Conference, Dublin, Ireland.

Huberman, B. A., \& Glance, N. (1993). Evolutionary games and computer simulations. Proceeedings of the National academy of Sciences, 90, 7716-7718. http://dx.doi.org/10.1073/pnas.90.16.7716

Håkansson, H., \& Prenkert, F. (2004). Exploring the Exchange Concept in Marketing. In H. Håkansson, D. Harrison \& A. Waluszewski (Eds.), Rethinking Marketing: Developing a New Understanding of Markets (pp. 75-97). Chichester: John Wiley \& Sons.

Håkansson, H., \& Snehota, I. (Eds.). (1995). Developing Relationships in Business Networks. London: Routledge.

Håkansson, H., \& Waluszewski, A. (2002). Path Dependence: Restricting or Facilitating Technical Development? Journal of Business Research, 55(7), 561-570. http://dx.doi.org/10.1016/S0148-2963(00)00196-X

Leik, R. K., \& Meeker, B. F. (1975). Mathematical sociology. Englewood-Cliffs, NJ: Prentice-Hall.

Louie, M. A., \& Carley, K. M. (2008). Balancing the criticisms: Validating multi-agent models of social systems. Simulation Modelling Practice and Theory, 16, 242-256. http://dx.doi.org/10.1016/j.simpat.2007.11.011

Luft, J., \& Shields, M. D. (2003). Mapping Management Accounting: Graphics and Guidelines for Theory-Consistent Empirical Research. Accounting, Organizations and Society, 28(2-3), 169-249. http://dx.doi.org/10.1016/S0361-3682(02)00026-0

Medlin, C. J. (2004). Interaction in Business Relationships: A Time Perspective. Industrial Marketing Management, 33(3), 185-193. http://dx.doi.org/10.1016/j.indmarman.2003.10.008

Midgley, D., Marks, R., \& Kunchamwar, D. (2007). Building and assurance of agent-based models: An example and challenge to the field. Journal of Business Research, 60(8), 884-893. http://dx.doi.org/10.1016/j.jbusres.2007.02.004

Miles, M. B., \& Huberman, A. M. (1994). Qualitative Data Analysis. An Expanded Sourcebook (2nd ed.). Thousand Oaks, Cal.: Sage Publications.

Miller, J. (1998). Active Nonlinear Tests (ANTs) of Complex Simulations Models. Management Science, 44(6), 
820-830. http://dx.doi.org/10.1287/mnsc.44.6.820

Morgan, G., \& Smircich, L. (1980). The Case for Qualitative Research. Academy of Management Review, 5(4), 491-500.

Moss, S., \& Edmonds, B. (2005). Sociology and Simulation: Statistical and Qualitative Cross-Validation. American Journal of Sociology, 110(4), 1095-1131. http://dx.doi.org/10.1086/427320

Newell, A., \& Simon, H. A. (1972). Human Problem Solving. Englewood Cliffs, N.J.: Prentice-Hall. PMCid:251293

Olaru, D., Denize, S., \& Purchase, S. L. (2009). Alternative ways of verification and validation of computational models: A case of replication in the innovation networks. Paper presented at the The 25th annual IMP-conference, Marseille, France.

Pettigrew, A. (1997). What is Processual Analysis? Scandinavian Journal of Management, 13(4), 337-348. http://dx.doi.org/10.1016/S0956-5221(97)00020-1

Ragin, C. C. (1992). 'Casing' and the Process of Social Inquiry. In C. Ragin \& H. S. Becker (Eds.), What is a Case: Exploring the Foundations of Social Inquiry (pp. 217-226). Cambridge: Cambridge University Press.

Ragin, C. C. (2000). Fuzzy-set Social Science. Chicago, Ill.: University of Chicago Press.

Railsback, S. F., \& Grimm, V. (2012). Agent-Based and Individual-Based Modeling: A Practical Introduction. Princeton and Oxford: Princeton University Press.

Robinson, S. (2005). Discrete-event simulation: from the pioneers to the present, what next? Journal of the Operations Research Society, 56, 619-629. http://dx.doi.org/10.1057/palgrave.jors.2601864

Rosenblueth, A., Wiener, N., \& Bigelow, J. (1943). Behavior, Purpose and Teleology. Philosophy of Science, 10(18). http://dx.doi.org/10.1086/286788

Ryan, A., Tähtinen, J., Vanharanta, M., \& Mainela, T. (2012). Putting critical realism to work in the study of business relationship processes. Industrial Marketing Management, $41(2), \quad 300-311$. http://dx.doi.org/10.1016/j.indmarman.2012.01.011

Schroeder, M. (1991). Fractals, chaos, power laws. New York: Freeman.

Scott Poole, M. (2004). Central issues in the study of change and innovation. In M. Scott Poole \& A. H. Van de Ven (Eds.), Handbook of Organizational Change and Innovation (pp. 3-31). New York: Oxford University Press.

Simon, H. A. (1955). A Behavioral Model of Rational Choice. Quarterly Journal of Economics, 69, 99-118. http://dx.doi.org/10.2307/1884852

Simon, H. A. (1976). From 'Bounded' to 'Procedural' Rationality. In S. Latsis (Ed.), Method and Appraisal in Economics. Cambridge, Mass.: Cambridge University Press. http://dx.doi.org/10.1017/CBO9780511572203.006

Troitzsch, K. G. (1994). Validating simulation models. Paper presented at the 18th European Simulation Multiconference, SCS Europe, SCS Europe.

von Wright, G. H. (1971). Explanation and Understanding. London: Routledge \& Kegan Paul.

Wilensky, U., \& Rand, W. (2007). Making Models Match: Replicating an Agent-Based Model. Journal of Artificial Societies and Social Simulation, 10(4), 1-22.

Wilkinson, I. F. (2008). Business Relating Business: Managing Organisational Relations and Networks. Cheltenham: Edvard Elgar.

Note

Note 1. Empirical curiosities as well as the wider theoretical backdrop concerning conceptualizations of 'relationship strength', 'adaptation' and 'embeddedness' is omitted here due to space restrictions, but can be found in Følgesvold \& Prenkert (2009), in which the herring model was originally reported. 


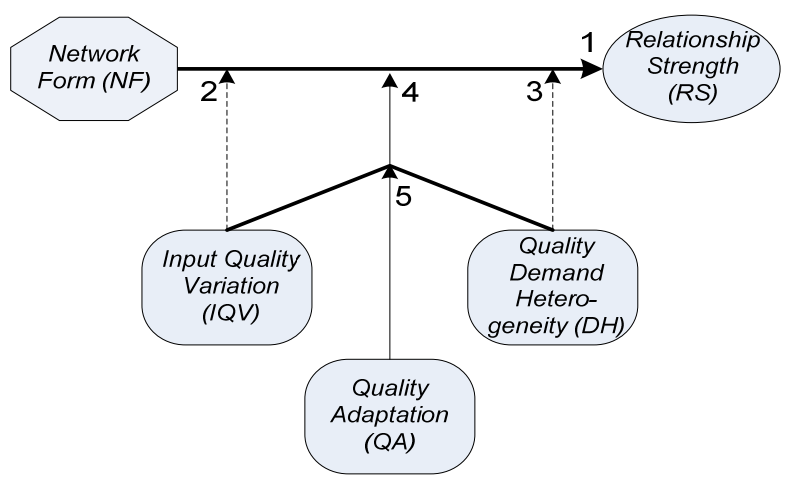

Figure 1. The causal model specification of the agent-based model targeting the North Atlantic Herring Network ' $\mathrm{NF}$ ' is the independent variable and 'RS' the dependent variable. 'IQV', 'QA' and 'DH' are mediating variables. The solid arrow 1 indicates a direct causal influence. The dotted arrows 2 and 3 indicate isolated mediating influence. Solid arrow 4 indicates and interactive mediating influence; and the solid arrow 5 indicates a direct mediating influence on the interactive mediating influence of 4. Developed from Følgesvold \& Prenkert (2009: 534). 